\title{
Modulation Model of High Frequency Band Radar Backscatter by the Internal Wave Based on the Third-Order Statistics
}

\author{
Pengzhen Chen ${ }^{1,2,3}$, Lei Liu ${ }^{4}$, Xiaoqing Wang ${ }^{5}$, Jinsong Chong ${ }^{1,2, *}$, Xin Zhang ${ }^{1,2}$ and \\ Xiangzhen $\mathrm{Yu}^{6}$ \\ 1 National Key Laboratory of Science and Technology on Microwave Imaging, Beijing 100190, China; \\ cpz0820@sina.com (P.C.); zhxinw@vip.163.com (X.Z.) \\ 2 Institute of Electronics, Chinese Academy of Sciences, Beijing 100190, China \\ 3 School of Electronics, Electrical and Communication Engineering, University of Chinese \\ Academy of Sciences, Beijing 100190, China \\ 4 Institute of Spacecraft System Engineering, China Academy of Space Technology, Beijing 100094, China; \\ liulei211@126.com \\ 5 Institute of Microelectronics of Chinese Academy of Sciences, Beijing 100029, China; huadaqq@126.com \\ 6 Shanghai Radio Equipment Institute, Shanghai 200090, China; yxz8302@163.com \\ * Correspondence: iecas_chong@163.com; Tel.: +86-135-0100-8982
}

Academic Editors: Xiaofeng Yang, Xiaofeng Li, Ferdinando Nunziata, Alexis Mouche and Prasad S. Thenkabail Received: 31 March 2017; Accepted: 17 May 2017; Published: 19 May 2017

\begin{abstract}
Modulation model of radar backscatters is an important topic in the remote sensing of oceanic internal wave by synthetic aperture radar (SAR). Previous studies related with the modulation models were analyzed mainly based on the hypothesis that ocean surface waves are Gaussian distributed. However, this is not always true for the complicated ocean environment. Research has showed that the measurements are usually larger than the values predicted by modulation models for the high frequency radars (X-band and above). In this paper, a new modulation model was proposed which takes the third-order statistics of the ocean surface into account. It takes the situation into consideration that the surface waves are Non-Gaussian distributed under some conditions. The model can explain the discrepancy between the measurements and the values calculated by the traditional models in theory. Furthermore, it can accurately predict the modulation for the higher frequency band. The model was verified by the experimental measurements recorded in a wind wave tank. Further discussion was made about applicability of this model that it performs better in the prediction of radar backscatter modulation compared with the traditional modulation model for the high frequency band radar or under lager wind speeds.
\end{abstract}

Keywords: radar backscatter; modulation model; internal wave; third-order statistics; high frequency band radar

\section{Introduction}

Internal waves usually result from the sharp density change occurring along the interface of the stratified density structure of the two fluids and travel with the interior of a fluid [1]. In the process of SAR imaging of internal waves, the internal wave firstly induce the variable current. Then, the current will directly interact with the surface waves, which results in the modulation of the radar backscatters [2]. Therefore, modulation model building is very crucial for the study of interaction between the radar backscatter and internal wave.

Many joint experiments, such as SAXON-FPN [3] (the Synthetic Aperture Radar and X Band Ocean Nonlinearities-Forschungs-platform Nordsee), JOWIP [4] (Joint Canada-U.S. Ocean Wave 
Investigation Project), SARSEX [5] (SAR Internal Wave Signature Experiment), CoastWatch-95 [6], and SCSE [7] (South China Sea Experiment) were carried out and in situ measurements [8-12] were made to investigate the modulation mechanism of radar backscatter. Weak hydrodynamic interaction theory [13-15] was used to describe the distribution of Bragg wave spectrum modulated by internal waves [2]. The imaging of internal waves is attributed to variations in the spectral energy density of Bragg waves induced by weak current variations associated with internal waves, similarly as the analysis of the imaging of bottom topography. A two-scale composite surface model derived from a modified Kirchhoff model is used to calculate the L-/X-band radar backscatter modulation [16]. A full-spectrum model of the modulation of internal wave is established taking account of the wave spectral perturbations over the entire spectrum of waves [17]. Existing models are mainly based on the assumption that fluctuation of heights on the water surface is a random Gaussian distribution.

However, the comparison between the theoretical model and experimental results showed that the measured modulation in SAR images is underestimated [17], especially for high frequency band (higher than X-band) radar signals. Some investigators pointed out that the contribution of the backscatter from breaking waves should not be ignored, especially for higher-band radar. RIM (Radar Imaging Model) [18] adds the energy source of breaking waves into the formation of a wave-current model. RIM simulates the wave modulation induced by convergent current taking account of breaking waves and finds that the spectral modulation of the shorter wave (between 10 and $1000 \mathrm{rad} / \mathrm{m}$ ) is larger than the modulation calculated by the wave-current model without waves breaking. The radar signatures of internal wave are more visible for $\mathrm{HH}$ polarization than $\mathrm{VV}$ polarization because of the impact of breaking waves, as reported in [7]. In substance, RIM adopts the improved hydrodynamic model, the composite surface model and Phillips's semi-empirical model [19] of breaking waves scattering to describe the scattering processing and explain the discrepancy of the modulation.

A modulation model of internal wave based on the third-order statistics of surface backscattering is proposed in this paper. It can effectively explain the discrepancy mentioned above by taking the non-Gaussian distribution of ocean surface slope into consideration. The IEM [20] (Integral Equation Model) was introduced to calculate radar backscatter coefficients. Compared with traditional models, the modulation model proposed in this paper combined the small perturbation method (SPM) [21] and the physics optical method (POM) [22], and it does not need to divide the ocean surface into different scales. As a result, the modulation of radar backscatter by internal wave could be calculated more precisely. The model explains the contradiction between the radar backscatter and the values predicted by traditional models. Experimental measurements were analyzed to verify the model. Information recorded by a CCD (Charge-coupled Device), which has high spatial and temporal resolution, was used to calculate the theoretical modulation attributed to second-order and third-order statistics. Results were compared with the data obtained by $\mathrm{X}$ and Ka band radar showing good agreement with the measured data by considering the third-order statistics. Moreover, these theoretical analyses and experimental observations demonstrate that the contribution of ocean surface third-order statistics to the modulation is significant for high frequency band radar. In other words, for high frequency band radar, it is necessary to add the contribution of ocean surface third-order statistics to the modulation by a variable surface current.

This paper is organized as follows: the modulation model of radar backscatter by internal wave based on the third-order statistics was derived in Section 2. In Section 3, an experiment was briefly described, as well as the data processing. In Section 4, results of experimental data were analyzed and discussed to validate the proposed model. Finally, main conclusions were given in Section 5.

\section{Modulation Model of Radar Backscatters by Internal Wave Based on Third-Order Statistics}

\subsection{Radar Backscatters of Ocean Surface Based on Third-Order Statistics}

An ocean surface scattering model, which is related to the ocean surface roughness spectrum, aims to quantify the relationship between the radar backscatter intensity and ocean surface statistics. 
The surface roughness spectrum is defined as the Fourier transform of the correlation of ocean surface wave [23], that is,

$$
W\left(k_{x}, k_{y}\right)=\frac{1}{4 \pi^{2}} \iint \sigma^{2} \rho(\xi, \zeta) \exp \left(-j k_{x} \xi-j k_{y} \zeta\right) d \xi d \zeta
$$

where $\sigma^{2} \rho(\xi, \zeta)$ is the second-order statistics of the surface wave $z(x, y)$ and can be calculated by Equation $(2), \rho(\xi, \zeta)$ is the correlation function of surface wave, and $\sigma^{2}$ is the variance of the surface wave height:

$$
\sigma^{2} \rho(\xi, \zeta)=\langle z(x, y) z(x+\xi, y+\zeta)\rangle
$$

where the $\langle\cdot\rangle$ stands for the ensemble average. Incorporating a non-Gaussian distribution of the surface wave height results in a difference between radar backscatters recorded downwind and upwind [24]. The skewness function $s(\xi, \zeta ; \tau, \varsigma)$ represents the distribution of the surface skewness coefficient [23]. It is commonly used to measure the departure from symmetry and can be calculated by

$$
\langle z(x, y) z(x+\xi, y+\zeta) z(x+\tau, y+\varsigma)\rangle=\sigma^{3} s(\xi, \zeta, \tau, \varsigma)
$$

The Fourier transform of the bicorrelation function $\sigma^{3} s(\xi, \zeta, \tau, \varsigma)$ is the bispectrum, that is,

$$
B\left(k_{x}, k_{y} ; \bar{k}_{x}, \bar{k}_{y}\right)=\frac{1}{16 \pi^{4}} \int \sigma^{3} s(\xi, \zeta ; \tau, \varsigma) \exp \left(-j k_{x} \xi-j k_{y} \zeta-j \bar{k}_{x} \tau-j \bar{k}_{y} \varsigma\right) d \xi d \zeta d \tau d \varsigma
$$

It is a function of four variables. Two special cases were considered in the following calculation of the model. When $\tau=\xi, \varsigma=\zeta$, we can get $\left\langle z(x, y) z^{2}(x+\xi, y+\zeta)\right\rangle=\sigma^{3} s(\xi, \zeta)$. For the case $\tau=\varsigma=0$, we can get $\left\langle z^{2}(x, y) z(x+\xi, y+\zeta)\right\rangle=\sigma^{3} s(-\xi,-\zeta)$. We can decompose the skewness function into two parts, the symmetric part $s_{s}(\xi, \zeta)$ and the asymmetric part $s_{a}(\xi, \zeta)$, as

$$
\begin{aligned}
& s_{s}(\xi, \zeta)=\frac{s(\xi, \zeta)+s(-\xi,-\zeta)}{2}, \\
& s_{a}(\xi, \zeta)=\frac{s(\xi, \zeta)-s(-\xi,-\zeta)}{2} .
\end{aligned}
$$

The bispectrum is the Fourier transform of $s(\xi, \zeta)$ and can be written as

$$
\begin{aligned}
B\left(k_{x}, k_{y}\right) & =B_{s}\left(k_{x}, k_{y}\right)+j B_{a}\left(k_{x}, k_{y}\right) \\
& =\frac{1}{2 \pi} \int \sigma^{3} s(\xi, \zeta) \mathrm{e}^{-j k_{x} \xi-j k_{y} \zeta} d \xi d \zeta \\
& =\frac{1}{2 \pi} \int \sigma^{3} \frac{s_{a}(\xi, \zeta)+s_{a}(\xi, \zeta)}{2} \mathrm{e}^{-j k_{x} \xi-j k_{y} \zeta} d \xi d \zeta
\end{aligned}
$$

where

$$
\begin{gathered}
B_{s}\left(k_{x}, k_{y}\right)=\frac{1}{2 \pi} \int \sigma^{3} s_{s}(\xi, \zeta) \exp \left(-j k_{x} \xi-j k_{y} \zeta\right) d \xi d \zeta \\
j B_{a}\left(k_{x}, k_{y}\right)=\frac{1}{2 \pi} \int \sigma^{3} s_{a}(\xi, \zeta) \exp \left(-j k_{x} \xi-j k_{y} \zeta\right) d \xi d \zeta
\end{gathered} .
$$

They present the symmetric and asymmetric property of the random ocean surface waves, respectively. Radar backscatters of the ocean surface can be further calculated (see Appendix A) by the theory of electromagnetic scattering [23]. That is,

$$
\sigma_{p p}^{0}=\frac{k^{2}}{4 \pi}\left|\Gamma_{p p}\right|^{2} \mathrm{e}^{-4 k_{z}^{2} \sigma^{2}} \iint\left\{\exp \left[4 k_{z}^{2} \sigma^{2} \rho(\xi, \zeta)+j 8 k_{z}^{3} \sigma^{3} s_{a}(\xi, \zeta)\right]-1\right\} \mathrm{e}^{-2 j k_{x} \xi} d \xi d \zeta
$$

where $k$ is the wavenumber of the radar, $\Gamma_{p p}$ is the coefficient defined as [23], $k_{z}=2 k \cos \theta$, and $k_{x}=2 k \sin \theta$. From Equation (9), we can see that the radar backscatter $\sigma_{p p}^{0}$ is a weighted value of the contribution of the second-order statistics $\sigma^{2} \rho(\xi, \zeta)$ and the third-order statistics $\sigma^{3} s_{a}(\xi, \zeta)$. The coefficient of the contribution is related to the $k_{z}$ and $\sigma$. 


\subsection{Modulation Transfer Function of Radar Backscatter by Internal Wave}

To simplify the following analysis, we name the modulation model that only considers the contribution of second-order statistics of ocean surface IEM2 model. The model with consideration of third-order statistics is called the IEM3 model.

Defining $\eta(\xi, \zeta)=\exp \left[4 k_{z}^{2} \sigma^{2} \rho(\xi, \zeta)+j 8 k_{z}^{3} \sigma^{3} s_{a}(\xi, \zeta)\right]-1$, we can get its Fourier transform as

$$
Q\left(k_{1}, k_{2}\right)=\iint\left\{\exp \left(4 k_{z}^{2} \sigma^{2} \rho(\xi, \zeta)+j 8 k_{z}^{3} \sigma^{3} s_{a}(\xi, \zeta)\right)-1\right\} \exp \left(-j k_{1} \xi-j k_{2} \zeta\right) d \xi d \zeta
$$

Therefore, Equation (9) can be rewritten as

$$
\sigma_{p p}^{0}=\frac{k^{2}}{4 \pi}\left|\Gamma_{p p}\right|^{2} \exp \left(-4 k_{z}^{2} \sigma^{2}\right) Q\left(2 k_{x}, 0\right)
$$

We can get the modulation transfer function of radar backscatter by internal wave, that is,

$$
\mathrm{M}_{\mathrm{IEM} 3}(k)=\frac{\widetilde{\sigma}_{p p}^{0}}{\sigma_{p p}^{0}}=\frac{\widetilde{Q}\left(2 k_{x}, 0\right)}{Q_{0}\left(2 k_{x}, 0\right)}
$$

where $\widetilde{\sigma}_{p p}^{0}$ and $\widetilde{Q}\left(2 k_{x}, 0\right)$ are the modulated radar backscatter and the spectrum, respectively. $Q_{0}\left(2 k_{x}, 0\right)$ is the background spectrum without modulation of internal waves.

For the case that the ocean surface is a Gaussian distribution, there will be no third-order component existing, $s_{a}(\xi, \zeta)=0$, and the radar backscatter is only attributed to the second-order statistics, Equation (9) can be rewritten as

$$
\sigma_{p p}^{0}=\frac{k^{2}}{4 \pi}\left|\Gamma_{p p}\right|^{2} \exp \left(-4 k_{z}^{2} \sigma^{2}\right) \mathrm{W}\left(2 k_{x}, 0\right),
$$

where $W\left(k_{1}, k_{2}\right)=\iint\left\{\exp \left(4 k_{z}^{2} \sigma^{2} \rho(\xi, \zeta)\right)-1\right\} \exp \left(-j k_{1} \xi-j k_{2} \zeta\right) d \xi d \zeta$. We can find that Equation (13) is the same with the expression in [25]. Similarly, the modulation of radar backscatter by internal wave can be obtained:

$$
\mathrm{M}_{\mathrm{IEM} 2}(k)=\frac{\widetilde{\sigma}_{p p}^{0}}{\sigma_{p p}^{0}}=\frac{\widetilde{W}\left(2 k_{x}, 0\right)}{W_{0}\left(2 k_{x}, 0\right)}
$$

where $\widetilde{\sigma}_{p p}^{0}$ and $\widetilde{W}\left(2 k_{x}, 0\right)$ are the modulated radar backscatter and the spectrum, respectively. $W_{0}\left(2 k_{x}, 0\right)$ is the background spectrum without modulation of internal waves.

We can see that Equations (12) and (14) are exactly the same when the ocean surface is Gaussian distributed. The contribution of third-order statistics can be ignored as long as $j 8 k_{z}^{3} \sigma^{3} s_{a}(\xi, \zeta) \ll$ $4 k_{z}^{2} \sigma^{2} \rho(\xi, \zeta)$ according to Equations (10)-(12). However, the value of $k_{z}$ usually becomes larger for the high frequency band radar that has a large wave number $k$, and $s_{a}(\xi, \zeta) \neq 0$ for the case of high wind speeds, which is likely resulting in the asymmetric distribution of the ocean surface. In this situation, the modulation of radar backscatter should include the contribution of third-order statistics. Therefore, it can explain the discrepancy between the measured radar backscatter and values calculated by traditional modulation models that only take the second-order statistics into consideration.

\section{Experimental Validation of the Model}

We used the data of wind-wave tank experiment to validate the model proposed in Section 2. Experiments were carried out in a large wind-wave tank filled with stratified water. The tank is $12 \mathrm{~m}$ $\times 1.2 \mathrm{~m} \times 1.2 \mathrm{~m}$ shown as Figure 1. Wind waves and internal wave were generated to simulate the condition of ocean surface. 


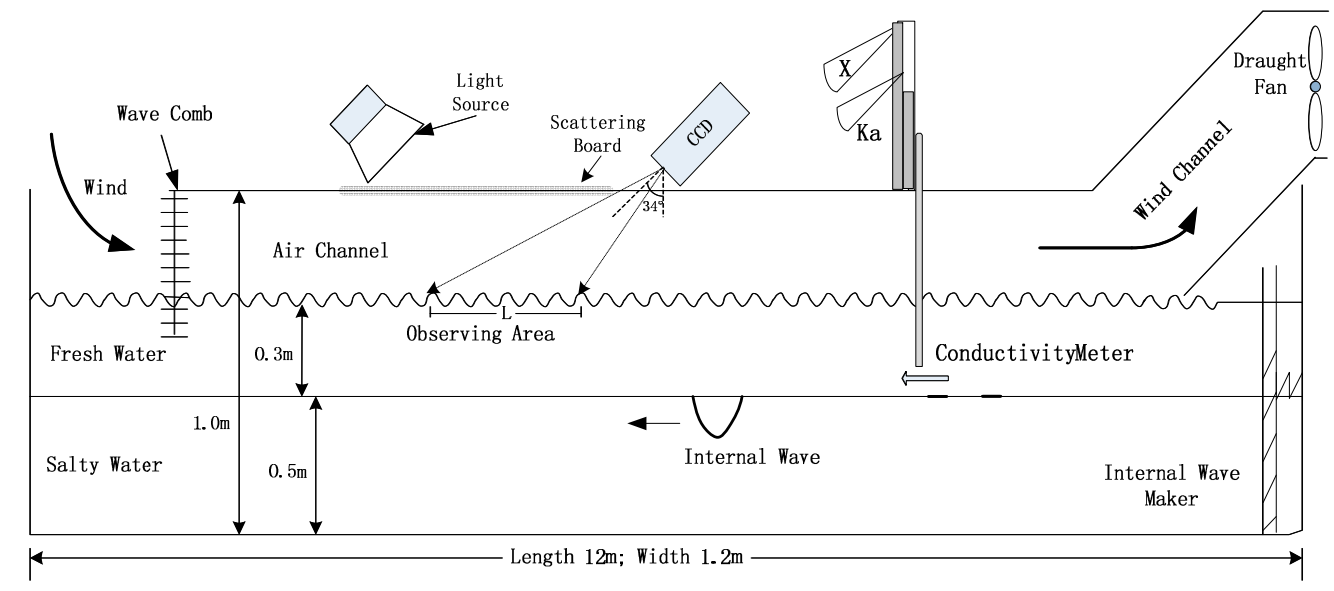

Figure 1. Schematic side view of the experimental wind-wave tank.

\subsection{Experiment Description}

$\mathrm{X}-/$ Ka-band radars and CCD were employed in experiments to record the modulation of reflected microwave signals by internal waves. Specifications of radar system are listed in Table 1.

Table 1. Specifications of radar system.

\begin{tabular}{ccc}
\hline Specifications & \multicolumn{2}{c}{ Values } \\
\hline Band & $X$ & $\mathrm{Ka}$ \\
Frequency & $9.4 \mathrm{GHz}$ & $35 \mathrm{GHz}$ \\
Beam Width & $9^{\circ} \times 9^{\circ}$ & $6^{\circ} \times 6^{\circ}$ \\
Incidence Angle & $50^{\circ}$ & $57^{\circ}$ \\
\hline
\end{tabular}

The CCD array has high spatial and temporal resolution. It was used to record the information of surface waves in the tank. As the optical system, it can obtain the wave slope by retrieving the intensity of reflected light from the water surface. Specifications of the CCD are listed in Table 2.

Table 2. Specifications of CCD.

\begin{tabular}{cc}
\hline Specifications & Values \\
\hline Swath Width & $36 \mathrm{~cm}$ \\
Resolution (Geometrical) & $0.3 \mathrm{~mm}$ \\
Frame Repetition & $300 \mathrm{~Hz}$ \\
Analog-to-Digital Convert Frequency & $300 \mathrm{KHz}$ \\
\hline
\end{tabular}

Radar system and CCD array are shown in Figure 2. 


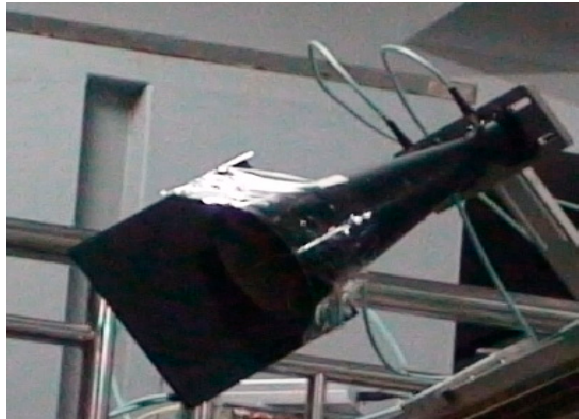

(a)

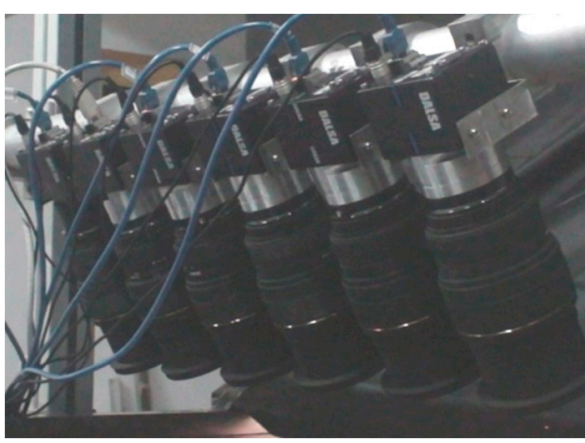

(b)

Figure 2. Experimental devices: (a) radar system; (b) CCD array.

Experiments were carried out under different experimental conditions. Table 3 shows the wind, internal wave and fetch parameters used during the experiments. $U_{w}$ is the wind speed measured in the air channel, and its corresponding $10 \mathrm{~m}$ wind speed is $U_{10} . D$ is the depth of the water. $F$ is the fetch where the surface waves were recorded. $D_{i}$ is the depth of the internal wave.

Table 3. Description of experiments.

\begin{tabular}{cccccc}
\hline & $\boldsymbol{U}_{\boldsymbol{w}}(\mathbf{m} / \mathbf{s})$ & $\boldsymbol{U}_{\mathbf{1 0}}(\mathrm{m} / \mathbf{s})$ & $\boldsymbol{D}(\mathbf{m} / \mathbf{s})$ & $\boldsymbol{F}(\mathbf{m})$ & $\boldsymbol{D}_{\boldsymbol{i}}(\mathbf{m})$ \\
\hline No. 1 & 3.2 & 4.1 & 0.8 & 5 & 0.3 \\
No. 2 & 4 & 5.2 & 0.8 & 5 & 0.3 \\
No. 3 & 5 & 6.9 & 0.8 & 5 & 0.3 \\
No. 4 & 6 & 8.6 & 0.8 & 5 & 0.3 \\
\hline
\end{tabular}

\subsection{Experimental Data Processing}

According to Bragg scattering theory [21] and parameters listed in Table 1, the frequencies of surface Bragg waves should be $11.3 \mathrm{~Hz}$ (X-band) and $61.8 \mathrm{~Hz}$ in theory. Moreover, the surface current and the orbital velocity of long surface wave which can be estimated by $V_{c}=0.6 u_{*}$ Ref. [26] also result in Doppler frequency shifts of $5.2 \mathrm{~Hz}$ and $20.3 \mathrm{~Hz}$ for the X-band and Ka-band radar, respectively. Figure 3 shows the Doppler spectrum of radar measured in the experiment at wind speed $4 \mathrm{~m} / \mathrm{s}$. It is reasonable that the center of the Doppler frequencies are mainly concentrated around $17 \mathrm{~Hz}(\mathrm{X})$ and 78 $\mathrm{Hz}(\mathrm{Ka})$ before the internal wave generated (200 s-400 s).

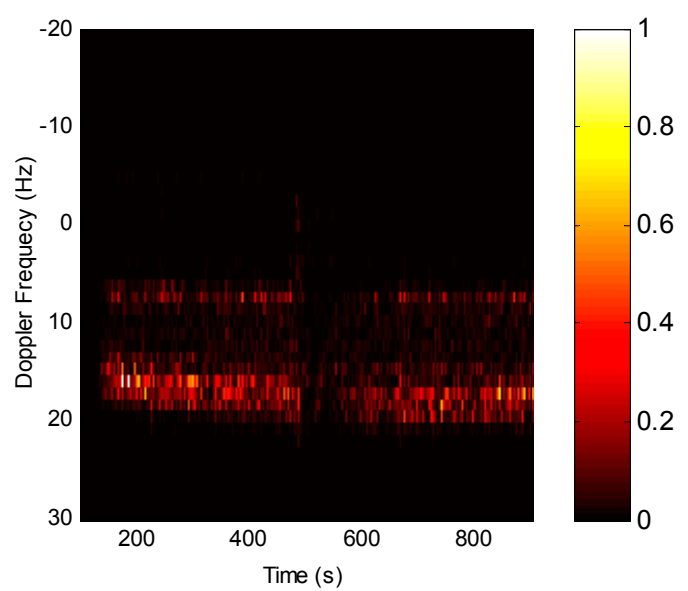

(a)

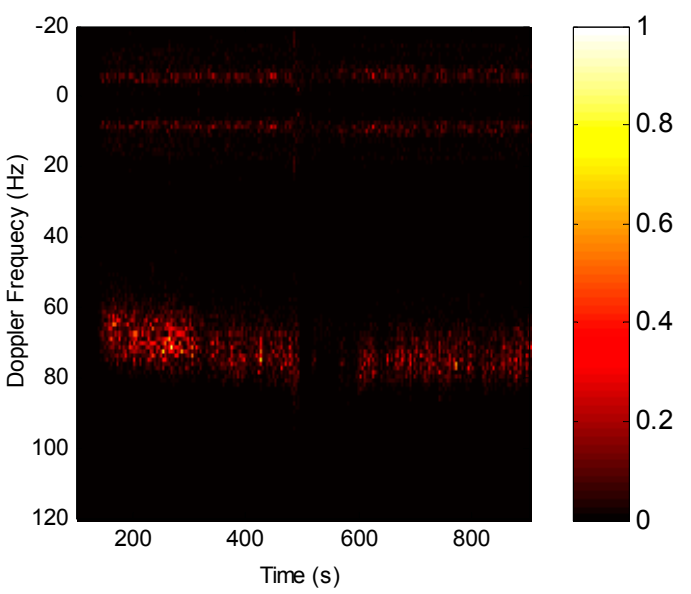

(b)

Figure 3. Doppler spectrum at the wind speed $4 \mathrm{~m} / \mathrm{s}$ (a) X band; (b) Ka band. 
We can also see that an interference frequency about $7 \mathrm{~Hz}$ was shown in Figure 3. It is caused by the echo data of water surface related to the antenna sidelobe. Therefore, we made the filtering in frequency domain in the following data processing.

The surface wave height can be obtained by integrating the surface slope recorded by CCD array. Figure $4 \mathrm{a}$ shows the water surface wave height recorded in $1 \mathrm{~s}$. Figure $4 \mathrm{~b}$ is the wave spectrum measured at different wind speeds. We can see that the spectrum increases with the increasing wind speed.

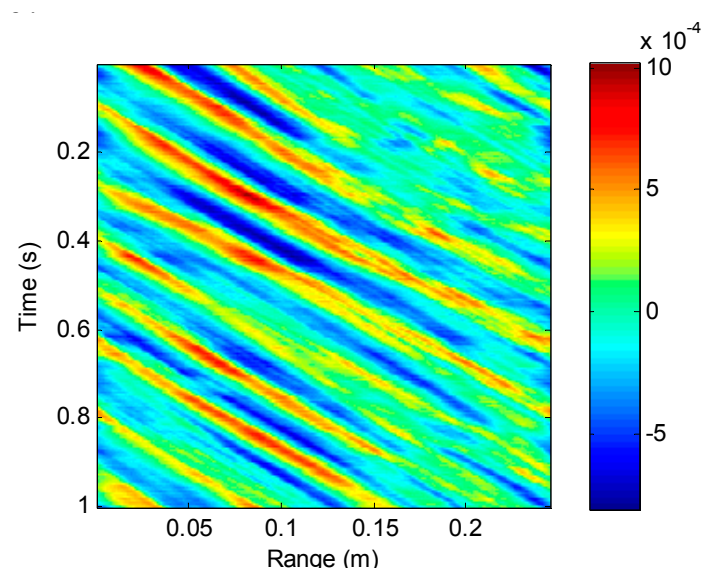

(a)

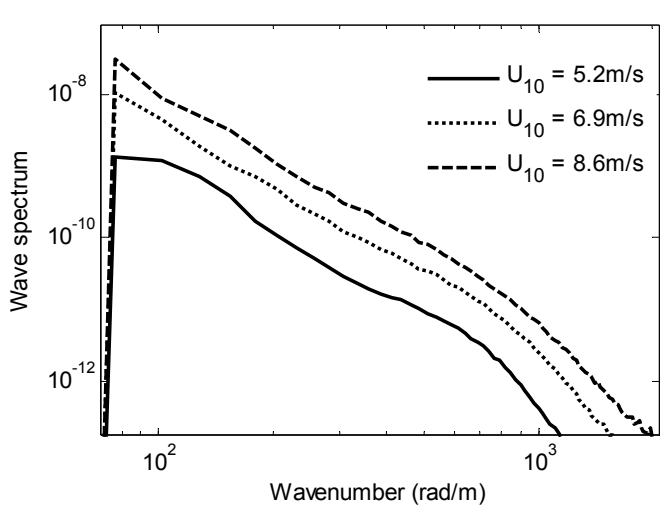

(b)

Figure 4. Surface wave recorded by CCD: (a) wave height; (b) wave spectra at different wind speeds.

\section{Results of Experiments and Discussion}

\subsection{Comparison between Radar Measurements and Values Calculated by Models}

Given the high spatial and temporal resolution of CCD array, we took CCD data as the input of modulation models to calculate the theoretic value. Radar systems used in the experiments were not calibrated. Therefore, we cannot measure the absolute value of radar backscatters. In the further data processing, we only calculate the change of the radar backscatter modulated by the internal wave.

Results of the IEM2 model, IEM3 model and contribution of the bispectrum were compared with the radar data as shown in Figure 5 . The $10 \mathrm{~m}$ wind speed is $5.2 \mathrm{~m} / \mathrm{s}$. Internal solitary wave passed by the observing area at $500 \mathrm{~s}$.

From Figure 5a, we can see that IEM2 modulation model can predict the modulation well for $\mathrm{X}$-band radar. However, the value predicted by IEM2 modulation model for Ka-band radar shown in Figure $5 b$ is smaller than the measured value about $5 \mathrm{~dB}$. As has been analyzed before, IEM2 modulation model only takes the second-order statistics of the ocean surface into consideration. It seems that the IEM2 model is not suitable for high frequency band radar. Moreover, the modulation of Ka-band radar backscatter shown in Figure $5 \mathrm{f}$ is larger than the $\mathrm{X}$-band radar backscatter as shown in Figure 5 e according to the measured radar data and the values calculated by the IEM3 model. This may result from the contribution of breaking waves or bound waves that commonly have a small wave length. They usually exist in the front of the long waves, resulting in the asymmetric distribution of the ocean surface. Therefore, it is reasonable that modulation of Ka-band radar calculated by IEM3 is larger than the result of IEM2, even larger than the modulation of X-band. 


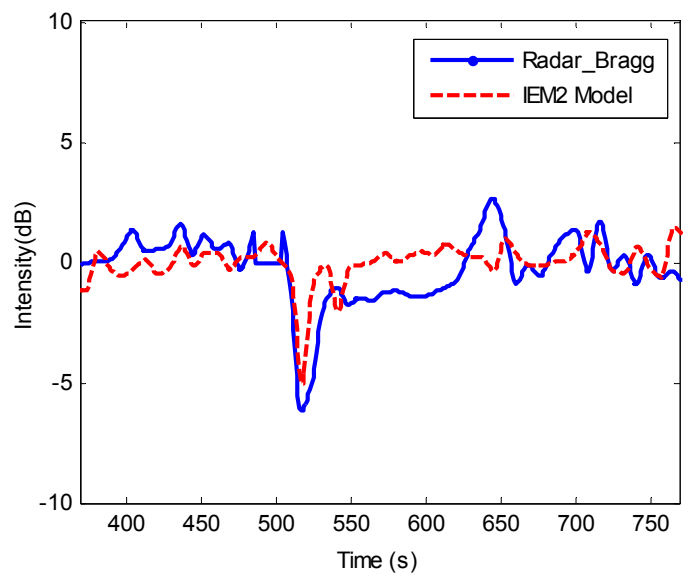

(a)

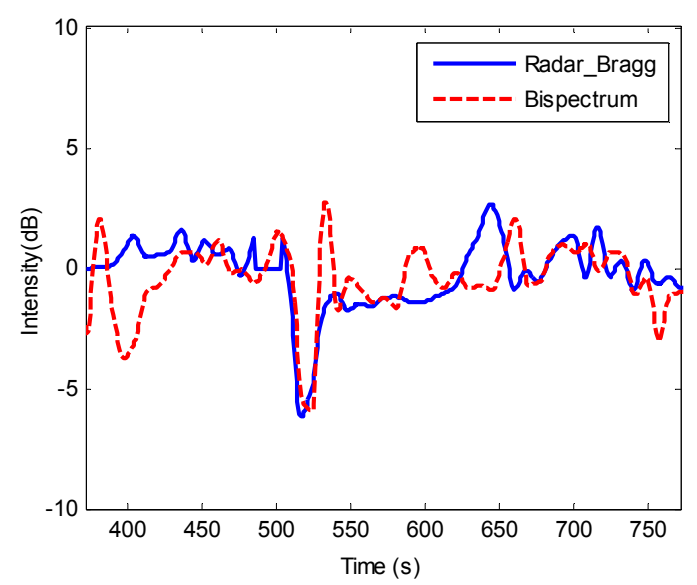

(c)

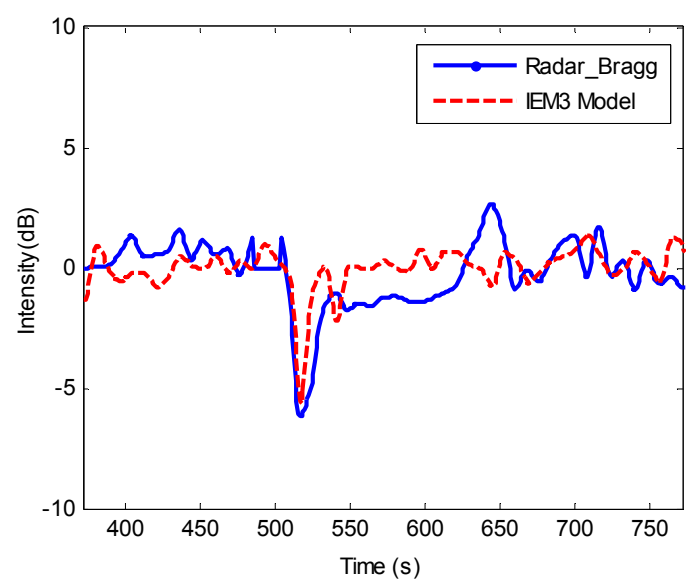

(e)

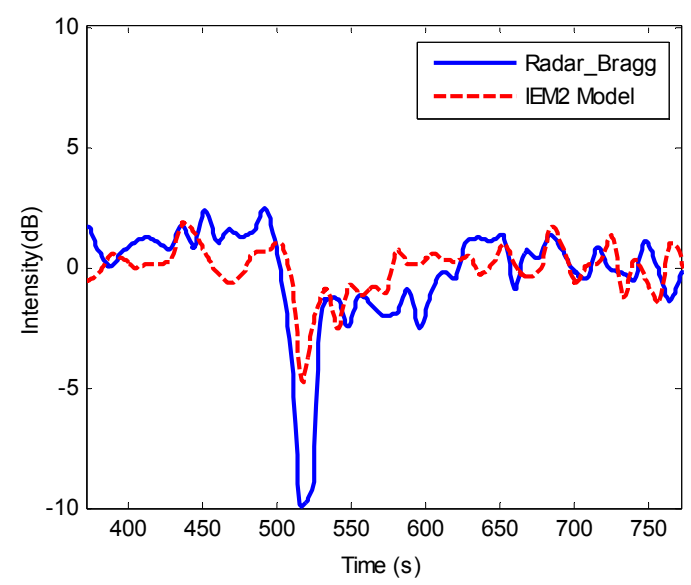

(b)

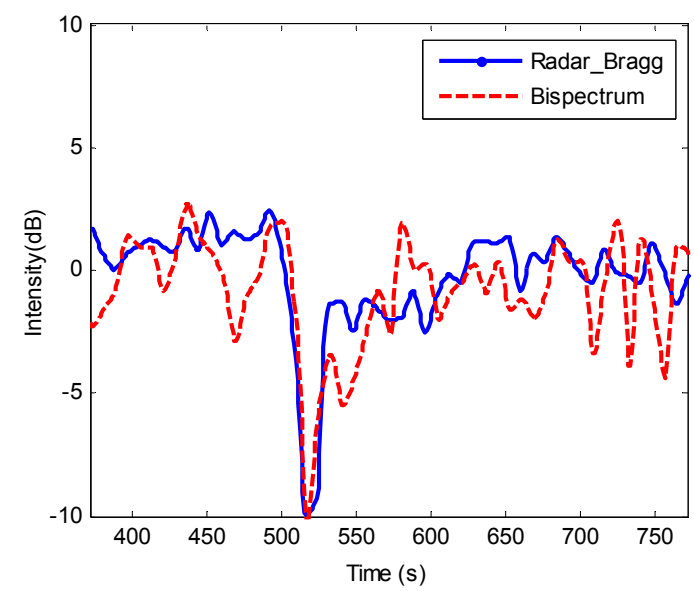

(d)

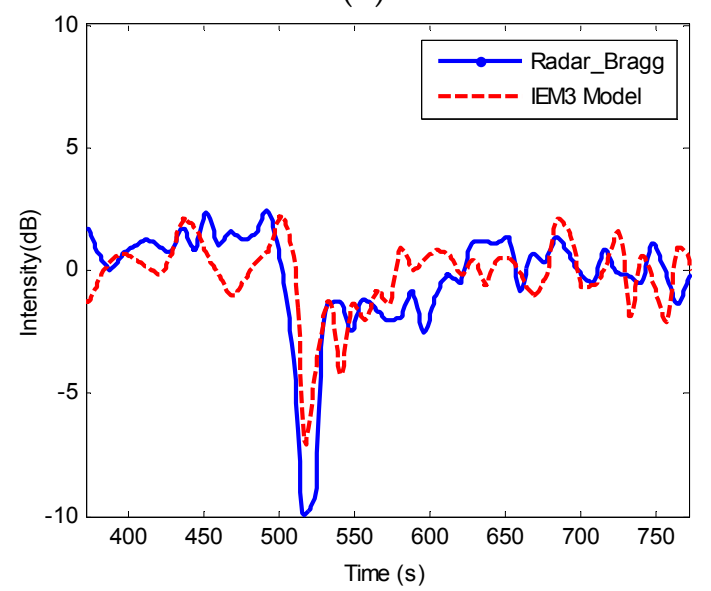

(f)

Figure 5. Comparison between measurements of radar and values calculated by models in theory. $10 \mathrm{~m}$ wind speed 5.2 m/s: (a) IEM2 Model vs. Radar: X-band; (b) IEM2 Model vs. Radar: Ka-band; (c) Bispectrum vs. Radar: X-band; (d) Bispectrum vs. Radar: Ka-band; (e) IEM3 Model vs. Radar: X-band; (f) IEM3 Model vs. Radar: Ka-band.

The IEM2 model describes the contribution of surface roughness spectrum of the ocean. On the contrast, modulation calculated by IEM3 model is a weighted sum of second-order statistics (surface roughness spectrum) and third-order statistics (bispectrum) according to Equation (10). Contribution 
of bispectrum was compared with the radar data in Figure $6 c, d$. We can see that the contribution of bispectrum is larger than the surface roughness spectrum for Ka-band radar from Figure 6b,d.

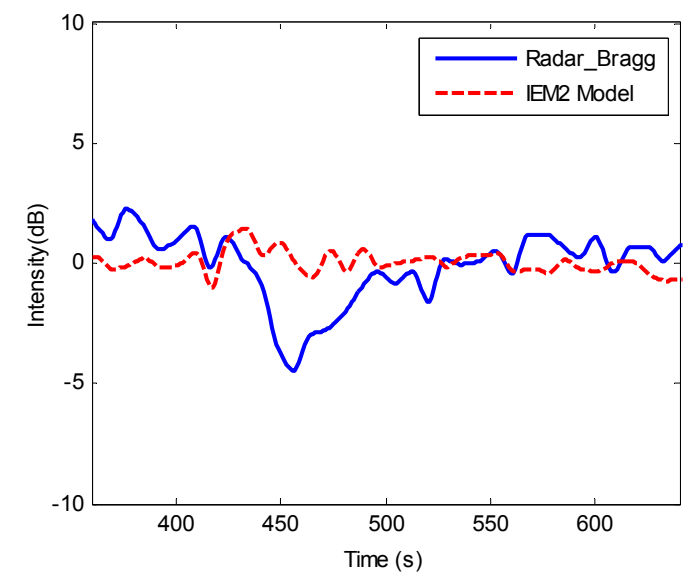

(a)

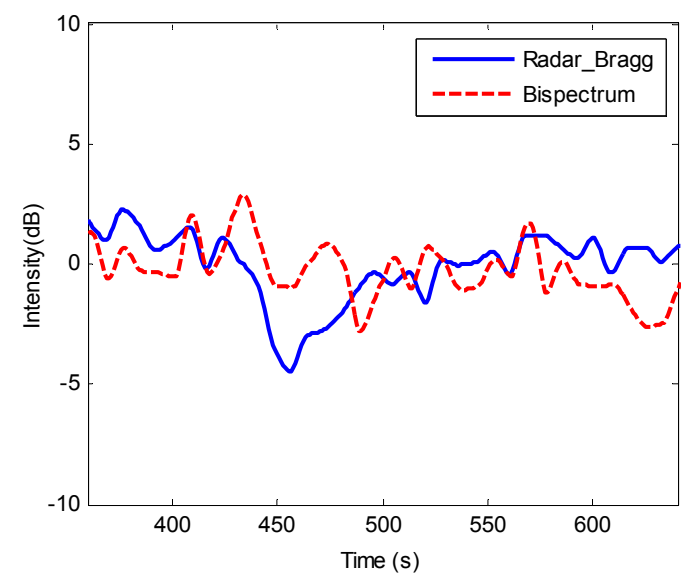

(c)

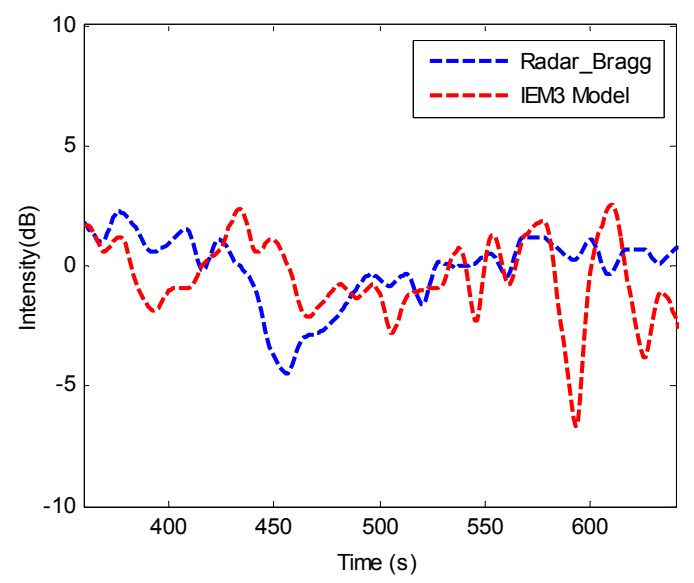

(e)

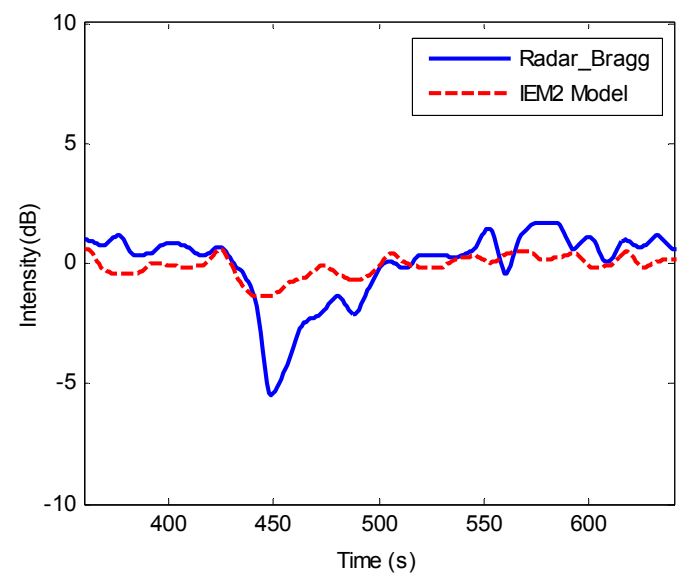

(b)

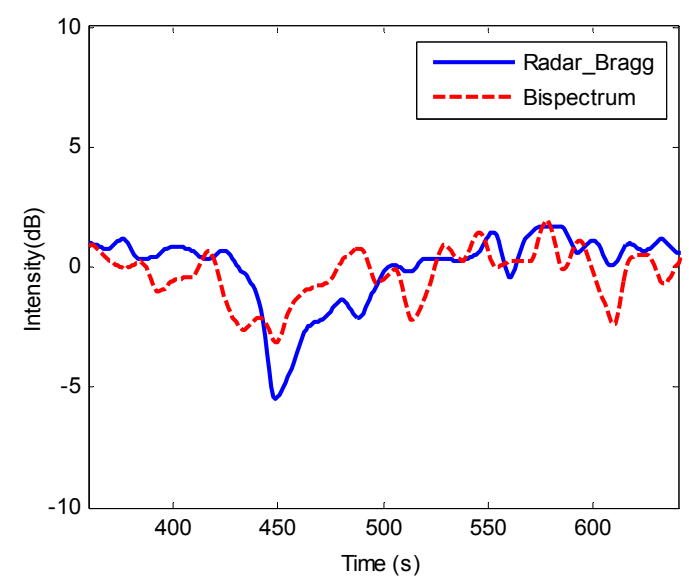

(d)

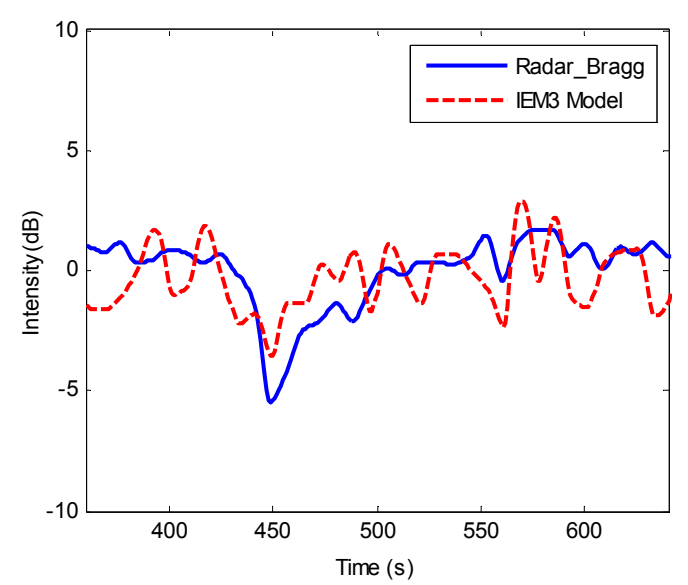

(f)

Figure 6. Comparison between measurements of radar and values calculated by models in theory, $10 \mathrm{~m}$ wind speed 6.9 m/s; (a) IEM2 Model vs. Radar: X-band; (b) IEM2 Model vs. Radar: Ka-band; (c) Bispectrum vs. Radar: X-band; (d) Bispectrum vs. Radar: Ka-band; (e) IEM3 Model vs. Radar: X-band; (f) IEM3 Model vs. Radar: Ka-band. 
Figure 6 shows the results at wind speed $6.9 \mathrm{~m} / \mathrm{s}$. Compared with Figure 5, the relaxation rates of the surface waves increase with the increasing wind speed. Correspondingly, the modulation of the intensity of the radar decreases about $3 \mathrm{~dB}$ for $\mathrm{X}$-band radar and $5 \mathrm{~dB}$ for Ka-band radar. The modulation estimated by IEM2 model can hardly be recognized as shown in Figure 6a,b. It was submerged under the signals of background and, as a consequence, the internal wave cannot be detected. On the contrast, predicted values of IEM3 model as shown in Figure 6e,f are closer to the radar data, which implies that the third-order statistics become increasingly important with the wind speed increasing.

\subsection{Relation between Modulation Depth of Radar Backscatter and Wind Speeds}

In this section, we will further discuss the modulation of high frequency band radar by internal waves at different wind speeds. To quantify the modulation, we introduce a new parameter modulation depth $\Delta M$ defined as

$$
\Delta M=\frac{\sigma_{\max }-\sigma_{\min }}{\sigma_{0}},
$$

where $\sigma_{0}$ is the backscatter coefficient of background, $\sigma_{\max }$ and $\sigma_{\min }$ are the maximum and minimum of the radar backscatter coefficient modulated by internal wave, respectively. We used the data recorded in the experiments at different wind speeds ranging from $4.1 \mathrm{~m} / \mathrm{s}$ to $8.6 \mathrm{~m} / \mathrm{s}$ and made the statistics. Results were compared with the predicted value of IEM2 and IEM3 models shown as in Figure 7.

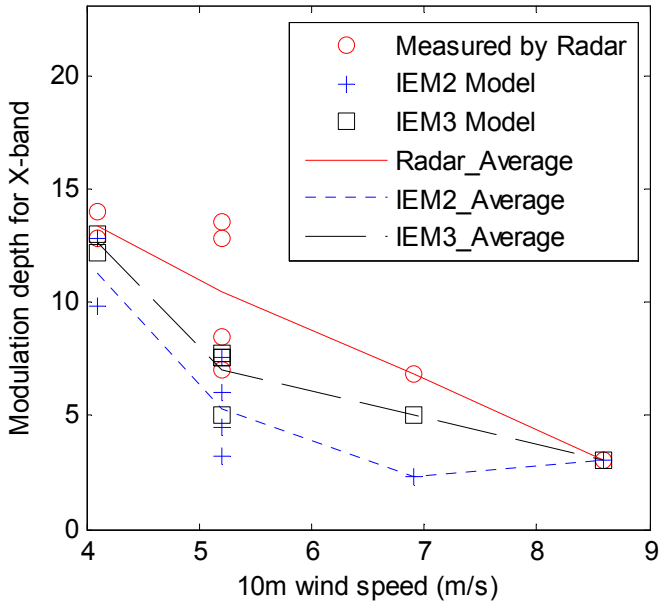

(a)

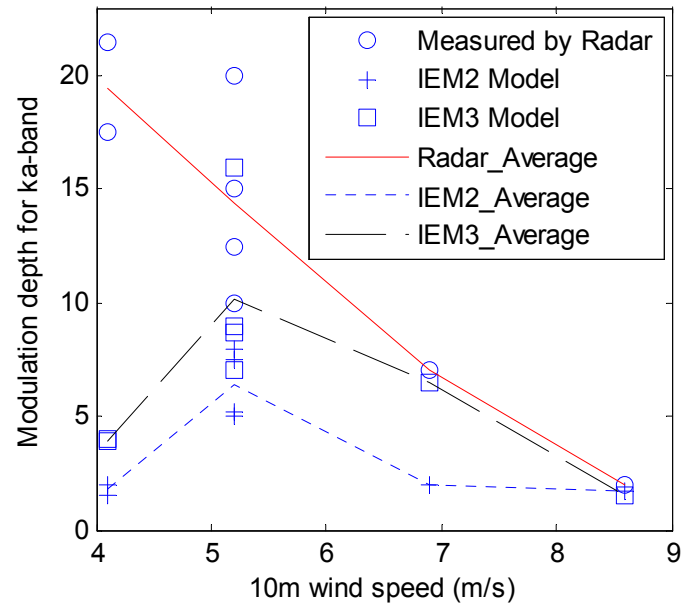

(b)

Figure 7. Modulation depth of radar backscatters as a function of wind speed: (a) X-band; (b) Ka-band.

We can see that all of the modulation depth measured by X-/Ka-band radar shows a decrease with increasing wind speed. It is similar for the predicted values calculated by modulated models except for Ka-band at $4.1 \mathrm{~m} / \mathrm{s}$. This is reasonable for the increasing wind speed corresponding to small relaxation rates $[27,28]$ of the surface Bragg waves. As a result, the effect of internal wave on surface wave spectrum decreases and results in small modulation depth.

Modulation depth calculated by the IEM3 model is superior to the results of the IEM2 model compared with the experimental measurements. The difference between them is more obviously for Ka-band than X-band. It is reasonable that Ka-band corresponds to a large $k_{z}$ and the contribution of third-order statistics has a large impact on the total scatters. As for the value calculated at wind speed $4.1 \mathrm{~m} / \mathrm{s}$ for Ka-band radar, this might be accounted for the few Bragg waves existing at low wind speed and the scatters mainly attributed to other sources, that is, multi-scattering or wedge scattering [29], which is not considered in the IEM3 model. 
The predicted values by IEM2 of X-band and Ka-band are very close at wind speed larger than $4.1 \mathrm{~m} / \mathrm{s}$. However, the modulation depth of X-band is smaller than the Ka-band predicted by IEM3. With the increasing wind speed, the contribution of bispectrum increases especially for the higher band radar.

\section{Conclusions}

In this paper, the discrepancy between traditional modulation model and the measurements of high frequency band radars are addressed. Based on the third-order statistics of ocean surface, a modulation model of high frequency band radar backscatters by internal wave was proposed. It takes the non-Gaussian distribution of the ocean surface into consideration.

Data of experiments conducted in a wind-wave tank was employed to evaluate performance of the proposed model. Modulation depth of radar backscatter coefficients were calculated based on the IEM model and compared with the measured results by X-/Ka-band radar. The IEM3 model that considers the third-order statistics shows a better consistency with the radar data than the IEM2 model. Further processing and analysis to the model were made and showed that the third-order statistics of ocean surface are more important to the high frequency band radar. The relation between modulation depth and wind speed are also given. The larger radar frequency as well as the wind speed corresponds to a greater weight to third-order statistics in the radar backscatters modulated by internal waves. For the Ka-band radar, there are some other scattering mechanisms at low wind speed, which will be explored in future studies.

This proposed model can be applied to high frequency band SAR imaging of internal waves. It can enhance the image quality and show more information. Furthermore, it can be used in other SAR's marine applications such as the imaging of sea bottom topography and eddies, since they consist of similar imaging mechanisms.

Acknowledgments: This work was supported by the National Natural Science Foundation of China (No. 61302166 and No. 41406206).

Author Contributions: Pengzhen Chen, Lei Liu and Xiaoqing Wang conceived and performed the experiments; Xiaoqing Wang and Jinsong Chong supervised and designed the research and made contribution to the article's organization; Xin Zhang Xiangzhen Yu and provided help for the manuscript revision. Pengzhen Chen and Lei Liu drafted the manuscript, which was revised by all authors. All authors have read and approved the final manuscript.

Conflicts of Interest: The authors declare no conflict of interest.

\section{Appendix A. Radar Backscatter Coefficient Function}

Radar backscatter coefficient is a function of average receiving power $p_{p p}$. It can be simplified by using IEM. Details are shown as follows:

$$
\begin{aligned}
P_{p p}= & \left\langle E_{p p}^{s} E_{p p}^{s} *^{*}\right\rangle-\left\langle E_{p p}^{s}\right\rangle\left\langle E_{p p}^{s}{ }^{*}\right\rangle \\
& =\left\langle E_{p p}^{k} E_{p p}^{k}\right\rangle-\left\langle E_{p p}^{k}\right\rangle\left\langle E_{p p}^{k}{ }^{*}\right\rangle+2 \operatorname{Re}\left[\left\langle E_{p p}^{c} E_{p p}^{k}{ }^{*}\right\rangle-\left\langle E_{p p}^{c}\right\rangle\left\langle E_{p p}^{k}{ }^{*}\right\rangle\right]+\left\langle E_{p p}^{c} E_{p p}^{c}{ }^{*}\right\rangle-\left\langle E_{p p}^{c}\right\rangle\left\langle E_{p p}^{c}{ }^{*}{ }^{\prime}\right.
\end{aligned}
$$

where $E_{p p}^{s}$ is the scattering electromagnetic field given by [20]. The right of Equation (A1) consists of three parts, and they are

$$
\begin{aligned}
& P_{p p}^{k}=\left\langle E_{p p}^{k} E_{p p}^{k}{ }^{*}\right\rangle-\left\langle E_{p p}^{k}\right\rangle\left\langle E_{p p}^{k}{ }^{*}\right\rangle \\
& P_{p p}^{k c}=2 \operatorname{Re}\left[\left\langle E_{p p}^{c} E_{p p}^{k}{ }^{*}-\left\langle E_{p p}^{c}\right\rangle\left\langle E_{p p}^{k}\right\rangle\right] .\right. \\
& P_{p p}^{c}=\left\langle E_{p p}^{c} E_{p p}^{c}{ }^{*}\right\rangle-\left\langle E_{p p}^{c}\right\rangle\left\langle E_{p p}^{c}{ }^{*}\right\rangle
\end{aligned}
$$

The scattering field $E_{p p}^{s}$ is

$$
E_{p p}^{s}=E_{p p}^{k}+E_{p p}^{c},
$$


where

$$
\begin{gathered}
E_{p p}^{k}=C E_{0} \int f_{p p} \exp \left(-j 2 \vec{k}_{i} \cdot \vec{r}\right) d x d y, \\
E_{p p}^{c}=\frac{C E_{0}}{8 \pi^{2}} \int F_{p p} \exp \left[-j \vec{k}_{i} \cdot \vec{r}-j \vec{k}_{i} \cdot \vec{r}^{\prime}+j u\left(x-x^{\prime}\right)+j v\left(y-y^{\prime}\right)\right] d x d y d x^{\prime} d y^{\prime} d u d v,
\end{gathered}
$$

where $E_{0}$ is the average transmitting power, $C=-j k e^{-j k R} / 4 \pi R$,. Therefore, the first item of Equation (A2) can be expressed as

$$
\begin{aligned}
P_{\mathrm{pP}}^{k}= & \left|C E_{0} f_{p p}\right|^{2}\left\langle\iint \mathrm{e}^{-j 2 \vec{k}_{i} \cdot \vec{r}+j 2 \vec{k}_{i} \cdot \vec{r}} d x d y d x^{\prime} d y^{\prime}\right\rangle-\left|C E_{0} f_{p p}\right|^{2}\left\langle\int \mathrm{e}^{-j 2 \vec{k}_{i} \cdot \vec{r}} d x d y\right\rangle\left\langle\int \mathrm{e}^{j 2 \vec{k}_{i} \cdot \vec{r}^{\prime}} d x^{\prime} d y^{\prime}\right\rangle \\
= & \left|C E_{0} f_{p p}\right|^{2} \iint\left\langle\mathrm{e}^{-j 2 k_{z}\left(z-z^{\prime}\right)}\right\rangle \mathrm{e}^{-j 2 k_{x}\left(x-x^{\prime}\right)-j 2 k_{y}\left(y-y^{\prime}\right)} d x d y d x^{\prime} d y^{\prime}- \\
& \left|C E_{0} f_{p p}\right|^{2}\left[\int\left\langle\mathrm{e}^{-j 2 k_{z} z}\right\rangle \mathrm{e}^{-j 2 k_{x} x-j 2 k_{y} y} d x d y\right]\left[\int\left\langle\mathrm{e}^{22 k_{z} z}\right\rangle \mathrm{e}^{j 2 k_{x} x^{\prime}+j 2 k_{y} y^{\prime}} d x^{\prime} d y^{\prime}\right]
\end{aligned} .
$$

Since the averages of the quantities referred in Equation (A6) can be placed by [20] ,

$$
\begin{aligned}
& \left\langle\mathrm{e}^{-j 2 k_{z}\left(z-z^{\prime}\right)}\right\rangle=\exp \left\{4 k_{z}^{2} \sigma^{2}[\rho(\xi, \zeta)-1]+j 8 k_{z}^{3} \sigma^{3} s_{a}(\xi, \zeta)\right\} \\
& \left\langle\mathrm{e}^{-j 2 k_{z} z}\right\rangle=\exp \left(-2 k_{z}^{2} \sigma^{2}+j 4 k_{z}^{3} \sigma^{3} / 3\right) \\
& \left\langle\mathrm{e}^{j 2 k_{z} z}\right\rangle=\exp \left(-2 k_{z}^{2} \sigma^{2}-j 4 k_{z}^{3} \sigma^{3} / 3\right)
\end{aligned} .
$$

Defining $x-x^{\prime}=\xi$ and $y-y^{\prime}=\zeta$, (A6) can then be further rewritten as

$$
\begin{aligned}
P_{\mathrm{pp}}^{k}= & \left|C E_{0} f_{p p}\right|^{2} \int \exp \left\{4 k_{z}^{2} \sigma^{2}[\rho(\xi, \zeta)-1]+j 8 k_{z}^{3} \sigma^{3} s_{a}(\xi, \zeta)\right\} e^{-j 2 k_{x} \xi-j 2 k_{y} \zeta} d \xi d \zeta- \\
& \left|C E_{0} f_{p p}\right|^{2} \int \exp \left(-2 k_{z}^{2} \sigma^{2}+j 4 k_{z}^{3} \sigma^{3} / 3\right) \exp \left(-2 k_{z}^{2} \sigma^{2}-j 4 k_{z}^{3} \sigma^{3} / 3\right) e^{-j 2 k_{x} \xi-j 2 k_{y} \zeta} d \xi d \zeta . \\
= & \left|C E_{0} f_{p p}\right|^{2} A_{0} e^{-4 k_{z}^{2} \sigma^{2}} \int\left\{\exp \left[4 k_{z}^{2} \sigma^{2} \rho(\xi, \zeta)+j 8 k_{z}^{3} \sigma^{3} s_{a}(\xi, \zeta)\right]-1\right\} e^{-j 2 k_{x} \xi-j 2 k_{y} \zeta} d \xi d \zeta
\end{aligned}
$$

For the second item in Equation (A2),

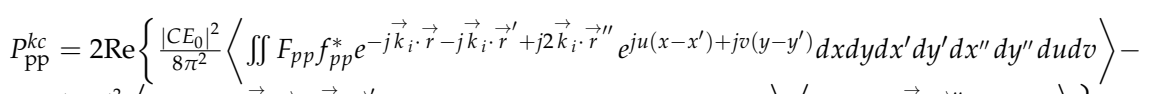

$$
\begin{aligned}
& \left.\frac{\left|C E_{0}\right|^{2}}{8 \pi^{2}}\left\langle\int F_{p p} e^{-j \vec{k}_{i} \cdot \vec{r}-j \vec{k}_{i} \cdot \vec{r}^{\prime}} e^{j u\left(x-x^{\prime}\right)+j v\left(y-y^{\prime}\right)} d x d y d x^{\prime} d y^{\prime} d u d v\right\rangle\left\langle\int f_{p p}^{*} e^{j 2 \vec{k}_{i} \cdot \vec{r}^{\prime \prime}} d x^{\prime \prime} d y^{\prime \prime}\right\rangle\right\}
\end{aligned}
$$

We take the situation that only single scattering occurs during the radar radiation, that is, $\vec{r}=\vec{r}^{\prime}$. Therefore, $x=x^{\prime}, y=y^{\prime}, x-x^{\prime \prime}=x^{\prime}-x^{\prime \prime}=\xi$, and $y-y^{\prime \prime}=y^{\prime}-y^{\prime \prime}=\zeta$. Equation (A9) can be further expressed as

$$
\begin{aligned}
P_{\mathrm{pp}}^{k c}=2 \operatorname{Re}\left\{\frac{\left|C E_{0}\right|^{2}}{8 \pi^{2}}\left\langle\iint F_{p p} f_{p p}^{*} e^{-2 j \vec{k}_{i} \cdot \vec{r}+j 2 \vec{k}_{i} \cdot \vec{r}^{\prime \prime}} d x d y d x^{\prime \prime} d y^{\prime \prime}\right\rangle-\frac{\left|C E_{0}\right|^{2}}{8 \pi^{2}}\left\langle\int F_{p p} e^{-2 j \vec{k}_{i} \cdot \vec{r}} d x d y\right\rangle\left\langle\int f_{p p}^{*} e^{j 2 \vec{k}_{i} \cdot \vec{r}^{\prime \prime}} d x^{\prime \prime} d y^{\prime \prime}\right\rangle\right\} \\
=2 \operatorname{Re}\left\{\frac{\left|C E_{0}\right|^{2}}{8 \pi^{2}} \iint F_{p p} f_{p p}^{*}\left\langle e^{-j 2 k_{z}\left(z-z^{\prime \prime}\right)}\right\rangle \mathrm{e}^{-j 2 k_{x}\left(x-x^{\prime \prime}\right)-j 2 k_{y}\left(y-y^{\prime \prime}\right)} d x d y d x^{\prime \prime} d y^{\prime \prime}-\right. \\
\left.\quad \frac{\left|C E_{0}\right|^{2}}{8 \pi^{2}}\left[\int F_{p p}\left\langle e^{-j 2 k_{z} z}\right\rangle \mathrm{e}^{-j 2 k_{x} x-j 2 k_{y} y} d x d y\right]\left[\int f_{p p}^{*}\left\langle e^{j 2 k_{z} z^{\prime \prime}}\right\rangle \mathrm{e}^{-j 2 k_{x} x^{\prime \prime}-j 2 k_{y} y^{\prime \prime}} d x^{\prime \prime} d y^{\prime \prime}\right]\right\}
\end{aligned}
$$

The third item in Equation (A2) is

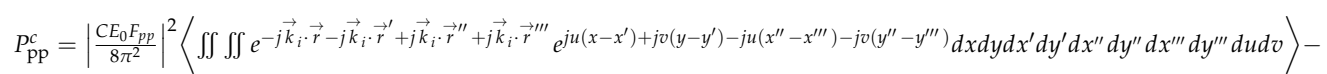

$$
\begin{aligned}
& \left|\frac{C E_{0}}{8 \pi^{2}}\right|^{2}\left\langle\iint F_{p p} e^{-j \vec{k}_{i} \cdot \vec{r}-j \vec{k}_{i} \cdot \vec{r}^{\prime}} e^{j u\left(x-x^{\prime}\right)+j v\left(y-y^{\prime}\right)} d x d y d x^{\prime} d y^{\prime} d u d v\right\rangle\left\langle\iint F_{p p}^{*} e^{i \vec{k}_{i} \cdot \vec{r}^{\prime \prime}+j \vec{k}_{i} \cdot \vec{r}^{\prime \prime \prime}} e^{-j u\left(x^{\prime \prime}-x^{\prime \prime \prime}\right)-j v\left(y^{\prime \prime}-y^{\prime \prime \prime}\right)} d x^{\prime \prime} d y^{\prime \prime} d x^{\prime \prime \prime} d y^{\prime \prime \prime} d u d v\right\rangle .
\end{aligned}
$$


For the same condition assumed above, we can get $\vec{r}=\vec{r}^{\prime}, \vec{r}^{\prime \prime}=\vec{r}^{\prime \prime \prime}, x=x^{\prime}, y=y^{\prime}$, and $x^{\prime \prime}=x^{\prime \prime \prime}, y^{\prime \prime}=y^{\prime \prime \prime}$. Therefore, we can further obtain

$$
\begin{gathered}
P_{\mathrm{pp}}^{c}=\left|\frac{C E_{0} F_{p p}}{8 \pi^{2}}\right|^{2}\left\langle\iint e^{-j 2 \vec{k}_{i} \cdot \vec{r}+2 j \vec{k}_{i} \cdot \vec{r}^{\prime \prime}} d x d y d x^{\prime \prime} d y^{\prime \prime}\right\rangle-\left|\frac{C E_{0}}{8 \pi^{2}}\right|^{2}\left\langle\int F_{p p} e^{-j 2 \vec{k}_{i} \cdot \vec{r}} d x d y\right\rangle\left\langle\iint F_{p p}^{*} e^{j i \vec{k}_{i} \cdot \vec{r}^{\prime \prime}} d x^{\prime \prime} d y^{\prime \prime}\right\rangle \\
=\left|\frac{C E_{0} F_{p p}}{8 \pi^{2}}\right|^{2} \iint\left\langle e^{-j 2 k_{z}\left(z-z^{\prime \prime}\right)}\right\rangle \mathrm{e}^{-j 2 k_{x}\left(x-x^{\prime \prime}\right)-j 2 k_{y}\left(y-y^{\prime \prime}\right)} d x d y d x^{\prime \prime} d y^{\prime \prime}- \\
\left.\left|\frac{C E_{0}}{8 \pi^{2}}\right|^{2} \mid \int F_{p p}\left\langle e^{-j 2 k_{z} z}\right\rangle \mathrm{e}^{-j 2 k_{x} x-j 2 k_{y} y} d x d y\right]\left[\int F_{p p}^{*}\left\langle\left\langle j 2 k_{z} z^{\prime \prime}\right\rangle \mathrm{e}^{-j 2 k_{x} x^{\prime \prime}-j 2 k_{y} y^{\prime \prime}} d x^{\prime \prime} d y^{\prime \prime}\right]\right.
\end{gathered}
$$

Defining $x-x^{\prime \prime}=\xi, y-y^{\prime \prime}=\zeta$, we can rewrite (A12) as

$$
\begin{aligned}
P_{\mathrm{pp}}^{c} & =\left|\frac{C E_{0} F_{p p}}{8 \pi^{2}}\right|^{2}\left[\int\left\langle e^{-j 2 k_{z}\left(z-z^{\prime \prime}\right)}\right\rangle \mathrm{e}^{-j 2 k_{x} \tilde{\xi}-j 2 k_{y} \zeta} d \xi d \zeta-\int\left\langle e^{-j 2 k_{z} z}\right\rangle\left\langle e^{j 2 k_{z} z^{\prime \prime}}\right\rangle \mathrm{e}^{-j 2 k_{x} \xi-j 2 k_{y} \zeta} d \xi d \zeta\right] . \\
& =\left|\frac{C E_{0} F_{p p}}{8 \pi^{2}}\right|^{2} A_{0} e^{-4 k_{z}^{2} \sigma^{2}} \int\left\{\exp \left[4 k_{z}^{2} \sigma^{2} \rho(\xi, \zeta)+j 8 k_{z}^{3} \sigma^{3} S_{a}(\xi, \zeta)\right]-1\right\} \mathrm{e}^{-j 2 k_{x} \tilde{\zeta}-j 2 k_{y} \zeta} d \xi \zeta \zeta
\end{aligned} .
$$

By substituting Equations (A2), (A8), (A10) (A13) into Equation (A1), we obtain

$$
\begin{aligned}
& P_{\mathrm{pp}}=P_{\mathrm{pp}}^{k}+P_{\mathrm{pp}}^{k c}+P_{\mathrm{pp}}^{c} \\
& =\left|C E_{0}\right|^{2}\left[\left|f_{p p}\right|^{2}-\frac{\operatorname{Re}\left(F_{p p} f_{p p}^{*}\right)}{4 \pi^{2}}+\frac{\left|F_{p p}\right|^{2}}{64 \pi^{4}}\right] \\
& e^{-4 k_{z}^{2} \sigma^{2}} \int\left\{\exp \left[4 k_{z}^{2} \sigma^{2} \rho(\xi, \zeta)+j 8 k_{z}^{3} \sigma^{3} s_{a}(\xi, \zeta)\right]-1\right\} \mathrm{e}^{-j 2 k_{x} \xi-j 2 k_{y} \zeta} d \xi d \zeta
\end{aligned},
$$

where $k_{x}=2 k_{0} \sin \theta, k_{z}=2 k_{0} \cos \theta, f_{p p}$ and $F_{p p}$ are coefficient defined by [20]. The radar backscatter coefficient $\sigma_{p p}^{0}$ is a function of $P_{p p}$, that is,

$$
\sigma_{p p}^{0}=4 \pi R^{2} \frac{P_{p p}}{E_{0}^{2} A_{0}}
$$

where $A_{0}$ is the area of antenna. Substitute Equation (A14) into Equation (A15) and use the method introduced in [25], we can get

$$
\begin{aligned}
& \sigma_{p p}^{0}= \frac{k^{2}}{4 \pi}\left[\left|f_{p p}\right|^{2}+\frac{1}{4 \pi^{2}} \operatorname{Re}\left(F_{p p} f_{p p}^{*}\right)+\frac{1}{64 \pi^{4}}\left|F_{p p}\right|^{2}\right] \mathrm{e}^{-4 k_{z}^{2} \sigma^{2}} \\
& \iint\left\{\exp \left[4 k_{z}^{2} \sigma^{2} \rho(\xi, \zeta)+j 8 k_{z}^{3} \sigma^{3} s_{a}(\xi, \zeta)\right]-1\right\} \mathrm{e}^{-2 j k_{x} \xi} d \xi d \zeta
\end{aligned} .
$$

Since $F_{p p}=\left[F_{p p}\left(k_{x}, 0\right)+F_{p p}\left(-k_{x}, 0\right)\right] / 2$, we can obtain

$$
\operatorname{Re}\left(F_{p p} f_{p p}^{*}\right)=\frac{F_{p p}\left(k_{x}, 0\right)+F_{p p}\left(-k_{x}, 0\right)}{4} f_{p p}^{*}+\frac{F_{p p}^{*}\left(k_{x}, 0\right)+F_{p p}^{*}\left(-k_{x}, 0\right)}{4} f_{p p} .
$$

By substituting Equation (A17) into Equation (A16), we can further get

$$
\sigma_{p p}^{0}=\frac{k^{2}}{4 \pi}\left|\Gamma_{p p}\right|^{2} \mathrm{e}^{-4 k_{z}^{2} \sigma^{2}} \iint\left\{\exp \left[4 k_{z}^{2} \sigma^{2} \rho(\xi, \zeta)+j 8 k_{z}^{3} \sigma^{3} s_{a}(\xi, \zeta)\right]-1\right\} \mathrm{e}^{-2 j k_{x} \xi} d \xi d \zeta,
$$

where

$$
\Gamma_{p p}=f_{p p}+\frac{1}{4 \pi^{2}}\left(\frac{F_{p p}\left(k_{x}, 0\right)+F_{p p}\left(-k_{x}, 0\right)}{4}\right)
$$

\section{References}

1. Jackson, C.R.; Apel, J.R. Syntheic Aperture Radar Marine User's Manual; NOAA/NESDIS: Washington, DC, USA, 2004.

2. Alpers, W. Theory of radar imaging of internal waves. Nature 1985, 314, 245-247. [CrossRef] 
3. Plant, W.J.; Alpers, W. The Saxon-FPN Experiment. In Proceedings of the IEEE Geoscience and Remote Sensing Symposium, Remote Sensing: Global Monitoring for Earth Management, Espoo, Finland, 3-6 June 1991; IEEE: New York, NY, USA, 1991.; pp. 1983-1987.

4. Hughes, B.A.; Dawson, T.W. Joint Canada-U.S. Ocean wave investigation project: An overview of the Georgia Strait experiment. J. Geophys. Res. Oceans 1988, 93, 12219-12234. [CrossRef]

5. Gasparovic, R.F.; Apel, J.R.; Kasischke, E.S. An overview of the sar internal wave signature experiment. J. Geophys. Res. Oceans 1988, 93, 12304-12316. [CrossRef]

6. Johanessen, J.A.; Korsbakken, E.; Samuel, P.; Jenkins, A.; Espedal, H. Coast watch: Using SAR imagery in an operational system for monitoring coastal currents, wind, surfactants and oil spills. In Operational Oceanography: The Challenge for European Co-Operation; Stel, J.H., Ed.; Elsevier: Amsterdam, The Netherlands, 1997.

7. Plant, W.J.; Keller, W.C.; Hayes, K.; Chatham, G.; Lederer, N. Normalized radar cross section of the sea for backscatter: 2. Modulation by internal waves. J. Geophys. Res. Oceans 2010, 115. [CrossRef]

8. Bai, X.; Liu, Z.; Li, X.; Chen, Z.; Hu, J.; Sun, Z.; Zhu, J. Observations of high-frequency internal waves in the Southern Taiwan Strait. J. Coast. Res. 2013, 29, 1413-1419. [CrossRef]

9. Li, X.; Jackson, C.R.; Pichel, W.G. Internal solitary wave refraction at Dongsha Atoll, South China Sea. Geophys. Res. Lett. 2013, 40, 3128-3132. [CrossRef]

10. Bai, X.; Liu, Z.; Li, X.; Hu, J. Generation sites of internal solitary waves in the Southern Taiwan Strait revealed by MODIS true-colour image observations. Int. J. Remote Sens. 2014, 35, 4086-4098. [CrossRef]

11. Liu, B.; Yang, H.; Zhao, Z.; Li, X. Internal solitary wave propagation observed by tandem satellites. Geophys. Res. Lett. 2014, 41, 2077-2085. [CrossRef]

12. Dong, D.; Yang, X.; Li, X.; Li, Z. SAR observation of eddy-induced mode-2 internal solitary waves in the South China Sea. IEEE Trans. Geosci. Remote Sens. 2016, 54, 6674-6686. [CrossRef]

13. Longuet-Higgins, M.S.; Stewart, R. Radiation stresses in water waves; a physical discussion, with applications. In Deep Sea Research and Oceanographic Abstracts; Elsevier: Amsterdam, The Netherlands, 1964; pp. 529-562.

14. Whitham, G. A general approach to linear and non-linear dispersive waves using a lagrangian. J. Fluid Mech. 1965, 22, 273-283. [CrossRef]

15. Bretherton, F.P. A note on hamilton's principle for perfect fluids. J. Fluid Mech. 1970, 44, 19-31. [CrossRef]

16. Thompson, D.R. Calculation of radar backscatter modulations from internal waves. J. Geophys. Res. Oceans 1988, 93, 12371-12380. [CrossRef]

17. Lyzenga, D.R.; Bennett, J.R. Full-spectrum modelling of synthetic aperture radar internal wave signatures. J. Geophys. Res. Oceans 1988, 93, 12345-12354. [CrossRef]

18. Kudryavtsev, V.; Akimov, D.; Johanessen, J.A.; Chapron, B. On radar imaging of current features: 1 . Model and comparison with observations. J. Geophys. Res. Oceans 2005, 110. [CrossRef]

19. Phillips, O.M. The Dynamics of the Upper Ocean, 2nd ed.; Cambridge University Press: Cambridge, UK, 1977; pp. 37-81.

20. Fung, A.K. Microwave Scattering and Emission Models and Their Applications; Artech House: London, UK, 1994.

21. Wright, J. A new model for sea clutter. IEEE Trans. Antennas Propag. 1968, 16, 217-223. [CrossRef]

22. Valenzuela, G.R. Theories for the interaction of electromagnetic and ocean waves-A review. Bound. Layer Meteorol. 1978, 13, 61-85. [CrossRef]

23. Chen, K.S.; Fung, A.K.; Weissman, D.A. A backscattering model for ocean surface. IEEE Trans. Geosci. Remote Sens. 1992, 30, 811-817. [CrossRef]

24. Plant, W.J. A new interpretation of sea-surface slope probability density functions. J. Geophys. Res. Oceans 2003, 108. [CrossRef]

25. Plant, W.J. A stochastic multiscale model of microwave backscatter from the ocean. J. Geophys. Res. Oceans 2002, 107, 3120. [CrossRef]

26. Plant, W.J.; Wright, J.W. Phase speeds of upwind and downwind traveling short gravity waves. J. Geophys. Res. Oceans 1980, 85, 3304-3310. [CrossRef]

27. Hughes, B.A. The effect of internal waves on surface wind waves 2. Theoretical analysis. J. Geophys. Res. Oceans 1978, 83, 455-465. [CrossRef] 
28. Plant, W.J. A relationship between wind stress and wave slope. J. Geophys. Res. Oceans 1982, 87, $1961-1967$. [CrossRef]

29. Plant, W.J.; Keller, W.C.; Hayes, K.; Chatham, G. Normalized radar cross section of the sea for backscatter: 1. Mean levels. J. Geophys. Res. Oceans 2010, 115. [CrossRef] 